\title{
SURGICAL REVERSAL OF VASECTOMY BY VAS ANASTOMOSIS
}

\author{
D. S. PARDANANI, M. L. KOTHARI, G. B. PARULKAR AND \\ P. G. JAYATILAK \\ Departments of Surgery and Anatomy, G.S. Medical College and \\ K.E.M. Hospital, Parel, Bombay-400 012, India
}

(Received 4th February 1974)

\begin{abstract}
Summary. Fifty vasectomized men were subjected to a modified technique of vas anastomosis operation. Thirty-five of the men were reviewed for periods ranging between 4 months and 2 years. Successful recanalization with reappearance of spermatozoa in the ejaculate was noted in thirty-one men $(89 \%)$, but the quality of their semen showed much variation. An analysis showed that the results were related to a number of clinical and operative factors. Spermatozoa were observed in the ejaculates of $70 \%$ of the men 4 months after the anastomosis operation. The number of oligospermic ejaculates became progressively less over the 2-year review period. The age of the patient and the duration between vasectomy and the vas anastomosis operation were also studied in relation to the spermiogram. The operative success and the failure rates were not related to the presence or the absence of whitish fluid in the lumen of the proximal vas segment at the time of the anastomosis or to the patients' fertility status before vasectomy. A comparatively low pregnancy rate following vas anastomosis operations requires to be further investigated.
\end{abstract}

\section{INTRODUCTION}

Vasectomy has become an important method of family planning and population regulation and, in recent years, there has been simultaneous increase in requests for vas re-anastomosis operations. The reported incidence of these requests varies between $0 \cdot 1 \%$ in Korea and 6 to $10 \%$ in the U.S.A. (Johnson, 1972). No information is available regarding the number of individuals who come for vas reconstruction in many other countries including India where vasectomy is a popular method of family limitation. Most of the requests for the recanalization operation are made because of loss of one or more children or because of remarriage, but there have been instances where bachelors and married men without children have undergone vasectomy for financial considerations. This is mainly seen in poorer countries, particularly where certain incentives are offered to the patients for undergoing vasectomy. It is realized that to maintain the present popularity and high acceptability of vasectomy as a method of family planning, methods must be devised by which, if necessary, vasectomy may be reversed and fertility restored. 
Recent reports have shown that recanalization of the vas deferens can be achieved in 70 to $90 \%$ of subjects (Phadke \& Phadke, 1967; Schmidt, 1968; Kar, 1969; Hulka \& Davis, 1972; Pardanani, Kothari, Mahendrakar \& Pradhan, 1973; Pardanani, Kothari, Pradhan \& Mahendrakar, 1974) but no attempt was made in the reported series to analyse the results on the basis of the spermiograms which were achieved or to relate the results to the various clinical and operative parameters. The availability of this information is considered important because a majority of the reported series have shown a very poor pregnancy rate following successful recanalization of the vas. Data obtained from such a study should lead to a greater understanding of the problems involved in achieving high success rates-both surgical and physiologicalfollowing the various vas anastomosis operations.

\section{MATERIALS AND METHODS}

Fifty unselected men who had undergone bilateral surgical vasectomy were subjected to the operation of anastomosis of the vas deferens. There were eighteen men in the age group of 21 to 30 years, nineteen in the age group of 31 to 40 years and thirteen in the age group of 41 to 50 years. At the time of vasectomy, ten men, though married, did not have children and four men were bachelors; the remaining thirty-six had one or more children. Twenty-two men had accepted vasectomy as a method for family limitation. Three had undergone the operation because of their financial difficulties. Eleven men stated that they did not 'clearly understand' the procedure and that they were 'misguided'; the authors felt that these men had undergone the operation to avail themselves of the incentives which were offered to them for accepting this operation. Five men, according to the clinical history obtained from their relatives, were prone to repeated episodes of mental depression; two of these, before undergoing vasectomy, had a quarrel in the family or with the spouse. A proper history relating to the indications for vasectomy could not be obtained for nine of the men.

Table 1. Duration between vasectomy and the vas anastomosis operation in fifty unselected men

\begin{tabular}{|c|c|c|c|c|c|c|c|c|c|c|c|c|c|c|}
\hline & 2 & 3 & 4 & 6 & 8 & 9 & $\begin{array}{c}\text { nths } \\
12\end{array}$ & 13 to 24 & 25 to 36 & 37 to 48 & 7 & & & 17 \\
\hline $\begin{array}{l}\text { No. of } \\
\text { subjects }\end{array}$ & 4 & 2 & 1 & 1 & 1 & 4 & 4 & 11 & 13 & 3 & 3 & 1 & 1 & 1 \\
\hline
\end{tabular}

Table 1 shows the duration between vasectomy and the vas anastomosis operation.

Twenty-one individuals in this series wanted to have their fertility restored because they had lost one or more children following vasectomy. Eight men wanted more children because they felt they could now financially support bigger families. Ten men, who did not have children at the time of vasectomy, wanted their vasectomies reversed because of their desire to have children. 
The individuals in this study were allotted to two groups depending upon the findings of the previous vasectomy (Pardanani, Kothari, Pradhan \& Mahendrakar, 1974). The 'unsatisfactory vasectomy' group included those in whom the vas had been sectioned in its lower convoluted portion near the cauda epididymidis ('convoluted-segment vasectomy') or in whom more than $2 \mathrm{~cm}$ of the vas had been excised ('long-segment vasectomy'). The 'satisfactory vasectomy' group included those who had a 'short-segment vasectomy' (less than $2 \mathrm{~cm}$ ) and in whom the vas had been sectioned in its straight segment well above the upper pole of the testis.

The operative technique of vas anastomosis used in the present series has already been described in detail (Pardanani, Kothari, Mahendrakar \& Pradhan, 1973).

The spermiograms were analysed on the basis of clinical parameters which included the age of the patient, the duration between vasectomy and the vas anastomosis operation, the duration of follow up after the vas anastomosis operation, and the patients' fertility status before vasectomy. On the basis of results of semen analysis, the individuals were classed as 'normospermic' (a minimum sperm count of $40 \times 10^{6} / \mathrm{ml}$, with a minimum of $50 \%$ spermatozoa showing Grade III motility at the end of $1 \mathrm{hr}$ after the collection of the semen, and a minimum normal sperm morphology of $60 \%$ ) or 'oligospermic' (lower values than those obtained for normospermic men).

Note was made of the presence or the absence of whitish, 'milky' fluid in the lumen of the proximal vas segment at the time of the anastomosis; an attempt was made to relate this observation to success and failure rates of the anastomosis operation.

\section{RESULTS}

Thirty-five of the fifty subjects in this series reported for review studies, including semen analyses; the duration of review in these cases varied between 4 months and 2 years.

The success and the failure rates of the vas anastomosis operation in this series are shown in Table 2. The results were based on reappearance of spermatozoa in the semen and on the occurrence of conception.

The data relating the subject's age to his semen quality are shown in Table 3. Of the fifteen normospermic men who were less than 40 years old, six $(40 \%)$ had relatively low sperm counts; of the five normospermic men in the older age

Table 2. Results of vas anastomosis operation

\begin{tabular}{c|c|c|c|c|c|c|c}
\hline \multirow{3}{*}{$\begin{array}{c}\text { No. of } \\
\text { subjects } \\
\text { reviewed }\end{array}$} & \multicolumn{3}{|c|}{ Overall results } & \multicolumn{3}{|c|}{ Results in 'satisfactory vasectomy' group } \\
\cline { 2 - 7 } & $\begin{array}{c}\text { Successful } \\
\text { vas } \\
\text { recanali- } \\
\text { zation }\end{array}$ & $\begin{array}{c}\text { Failure } \\
\text { of vas } \\
\text { recanali- } \\
\text { zation }\end{array}$ & Pregnancies & $\begin{array}{c}\text { No. of } \\
\text { subjects }\end{array}$ & $\begin{array}{c}\text { Successful } \\
\text { vas } \\
\text { recanali- } \\
\text { zation }\end{array}$ & $\begin{array}{c}\text { Failure } \\
\text { of vas } \\
\text { recanali- } \\
\text { zation }\end{array}$ & Pregnancies \\
\hline 35 & $\begin{array}{c}31 \\
(89 \%)\end{array}$ & 4 & $\begin{array}{c}11 \\
(35.5 \%)\end{array}$ & 29 & $\begin{array}{c}28 \\
(96.5 \%)\end{array}$ & 1 & 8 \\
\hline
\end{tabular}


Table 3. The relation of the age of the subject to the quality of the semen

\begin{tabular}{l|c|c}
\hline \multirow{1}{*}{ Age groups } & \multicolumn{2}{|c}{ Semen quality } \\
\cline { 2 - 3 } & Normospermia & Oligospermia \\
\hline $\begin{array}{l}\text { Less than } 40 \text { years } \\
\begin{array}{l}\text { (21 subjects) } \\
40 \text { years or more } \\
\text { (10 subjects) }\end{array}\end{array}$ & $15^{*}(71 \%)$ & $6(29 \%)$ \\
\hline
\end{tabular}

$\chi^{2}=0.584 ;$ d.f. $=1$, N.S.

* Six men $(40 \%)$ had relatively low sperm counts.

$\dagger$ Four men $(80 \%)$ had low sperm counts.

Table 4. The effect of duration between vasectomy and the vas anatomosis operation on the quality of the semen

\begin{tabular}{l|c|c|c|c|c|c}
\hline \multicolumn{1}{c|}{$\begin{array}{c}\text { Duration of } \\
\text { vasectomy }\end{array}$} & $\begin{array}{c}<12 \\
\text { months }\end{array}$ & $\begin{array}{c}12 \text { to } 23 \\
\text { months }\end{array}$ & $\begin{array}{c}24 \text { to } 35 \\
\text { months }\end{array}$ & $\begin{array}{c}>36 \\
\text { months }\end{array}$ & $\begin{array}{c}\text { Overall } \\
\text { results }\end{array}$ & Pregnancies \\
\hline $\begin{array}{l}\text { Normospermic subjects } \\
\text { No. }\end{array}$ & 10 & 5 & 4 & 1 & 20 & $\begin{array}{c}8 \\
\%\end{array}$ \\
$\begin{array}{l}\text { Oligospermic subjects } \\
\text { No. }\end{array}$ & $(91 \%)$ & $(62 \%)$ & $(80 \%)$ & $(14 \cdot 3 \%)$ & $(64.5 \%)$ & $(40 \%)$ \\
$\%$ & $(9 \%)$ & $(38 \%)$ & $(20 \%)$ & $\begin{array}{c}6 \\
(85.7 \%)\end{array}$ & $\begin{array}{c}11 \\
(35.5 \%)\end{array}$ & $\begin{array}{c}3 \\
(27 \%)\end{array}$ \\
\hline
\end{tabular}

group, four $(80 \%)$ had relatively low sperm counts. While it appears from this study that patients over the age of 40 years produce a poorer quality semen following the vas anastomosis operation, the data of a larger number should be analysed to show if this finding has any statistical significance.

The effect of lapse of time between vasectomy and vas anastomosis on semen quality is shown in Table 4. An analysis showed that the difference in the semen quality of those men for whom the duration of vasectomy was less than 3 years and those for whom the duration of vasectomy was 3 or more years was statistically significant $(P=0.0036$, Fisher's exact probability test).

The data relating semen quality following vas anastomosis to pregnancy rate are shown in Table 4. An analysis of the results from this relatively small number of individuals failed to show any statistical significance $(P>0.245$, N.S., Fisher's exact probability test).

Twenty-four men in this series were known to be fertile before vasectomy; successful vas recanalization was observed in twenty-two $(91.6 \%)$ of these men. For the remaining eleven men, no proof of fertility before vasectomy was available (four were bachelors and seven were married men with no children); successful vas recanalization was achieved in nine of these men $(82 \%)$. The difference in the success rates for these two groups was statistically not significant $(P>0 \cdot 290$, N.S., Fisher's exact probability test).

Spermatozoa appeared in the ejaculates of twenty-two men out of thirty-one $(71 \%) 4$ months after the anastomosis operation; the ejaculates of eight of 
Table 5. The relation of semen quality to the duration of review after the vas anastomosis operation

\begin{tabular}{c|c|c}
\hline \multirow{2}{*}{$\begin{array}{c}\text { Duration of } \\
\text { review }\end{array}$} & \multicolumn{2}{|c}{ Semen quality } \\
\cline { 2 - 3 } & Normospermia & Oligospermia \\
\hline $\begin{array}{c}\text { Less than 4 months } \\
\text { (6 subjects) }\end{array}$ & $3(50 \%)$ & $3(50 \%)$ \\
$\begin{array}{c}4 \text { months to 1 year } \\
\text { (19 subjects) }\end{array}$ & $12(63 \%)$ & $7(37 \%)$ \\
$\begin{array}{c}\text { More than 1 year } \\
(6 \text { subjects) }\end{array}$ & $5(83 \%)$ & $1(17 \%)$ \\
\hline
\end{tabular}

$\chi^{2}=0.718 ;$ d.f. $=2$, N.S. Kolmogorov-Smirnov twosample test.

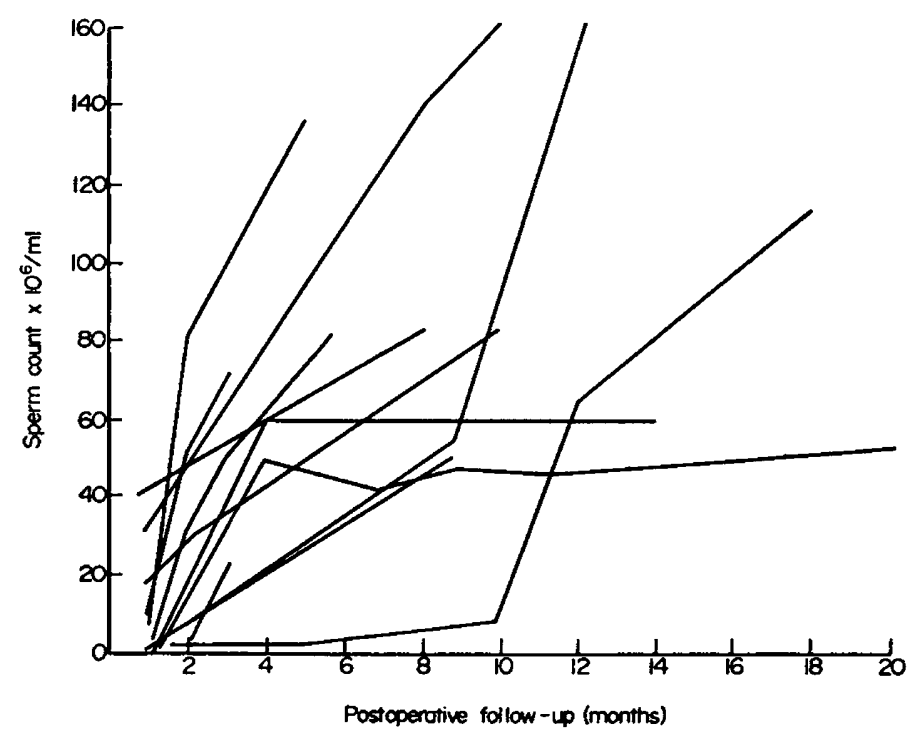

TEXT-FIG. 1. The curves show an increase in the sperm count in relation to the duration of follow-up after reanastomosis of the vas. In most subjects, there is a rapid rise in the sperm count during the first 4 to 6 months. In some subjects, the rise in the sperm count occurs gradually or is delayed.

these men had shown absence of spermatozoa during earlier semen analyses. By 6 months and 8 months after vas anastomosis, spermatozoa had reappeared in the semen of twenty-six $(84 \%)$ and thirty-one $(100 \%)$ men, respectively. The semen quality at different periods of time following vas anastomosis is analysed in Table 5. This analysis shows a trend for the numbers of normospermic individuals to increase and for the numbers of oligospermic individuals to decrease with the increasing duration of the review study (Text-fig. 1); owing to the small numbers of individuals, however, the results were not significant.

Of twenty-two men that were examined, thirteen had a copious flow of whitish fluid from the lumen of the proximal vas segment when it was sectioned; successful recanalization was achieved in all thirteen. Successful recanalization achieved in eight of nine men in whom this fluid was absent. The statistical 
difference in the results for these two groups was not significant $(P>0.409$, N.S., Fisher's exact probability test).

\section{DISGUSSION}

Success rates of the vas anastomosis operation

A surgical success rate of nearly $90 \%$ was obtained in a group of thirty-five unselected individuals who reported for review studies in this series.

It was shown in an earlier study that an unsatisfactory previous vasectomy adversely affected the results of the vas anastomosis operations (Pardanani, Kothari, Pradhan \& Mahendrakar, 1974). In the present study, of six subjects who had bilateral 'unsatisfactory vasectomy', successful recanalization was only achieved in three $(50 \%)$. This may be compared to twenty-eight out of twenty-nine $(96.5 \%)$ subjects for whom 'satisfactory vasectomy' was recorded.

It was observed that when the vas segment on the epididymal side was sectioned before anastomosis, a whitish, 'milky' fluid often flowed out from its lumen. This fluid contained non-motile or sluggishly motile spermatozoa and an amount of amorphous material and débris, but was not a constant finding. An analysis of the data for twenty-two subjects showed that the presence or the absence of this whitish fluid did not significantly affect the results of recanalization. Similarly, it was shown that knowledge of an individual's fertility status before vasectomy did not have any significant bearing on the success or the failure rates.

Analysis of the factors affecting semen quality and pregnancy rate after successful recanalization of the vas

Not all vasectomized men report the occurrence of pregnancy in their partners following successful recanalization. Approximately a third of the individuals in this series did so. Similar results have been reported by other workers (Hulka \& Davis, 1973). There is much speculation regarding the causes of this poor conception rate.

When assessing semen quality, it was necessary to take into account the duration of the review period after the operation. A sharp rise was noted in the sperm count in the successfully recanalized cases during the first 4 months following the operation; after this, the rise in the sperm count was more gradual (Text-fig. 1). Some individuals, however, continued to show improvement in their semen quality over periods extending up to 1 or more years. The occurrence of conception in the partners of these cases is likely to be delayed.

The reason for the better quality of semen observed in individuals who reported for the anastomosis operation within 3 years after vasectomy compared to the quality in those who reported for the operation 3 or more years after vasectomy is not known. A longer duration of vas obstruction might affect spermatogenesis directly or through alteration of the hormonal function of the testis or because of some auto-immune factors. Further clinical studies are required to evaluate the immunological consequences of vasectomy and to study the effects of various durations of occlusion of the vas deferens on the spermatogenic and steroidogenic functions of the testis. 


\section{AGKNOWLEDGMENTS}

We acknowledge with gratitude the encouragement and advice of Dr G. K. Deshpande, Dean, G. S. Medical College and K. E. M. Hospital and thank him for the facilities provided for this work at these Institutions. This study was supported by the Indian Council of Medical Research, New Delhi, India.

\section{REFERENCES}

Hulka, J. F. \& Davis, J. E. (1972) Vasectomy and reversible vasocclusion. Fert. Steril. 23, 683.

Johnson, D. S. (1972) Reversible male sterilization: current status and future directions. Contraception, $5,327$.

KAR, J. K. (1969) Surgical correction of post-vasectomy sterility. F. Family Welfare, 15, 50.

Pardanani, D. S., Kothari, M. L., Mahendrakar, M. N. \& Pradhan, S. A. (1973) The use of silicone rubber splint for post-vasectomy vas deferens anastomosis : report of a new operative technique. Contraception, 7, 491.

Pardanani, D. S., Kothari, M. L., Pradhan, S. A. \& Mahendrakar, M. N. (1974) Operative restoration of vas continuity after vasectomy: further clinical evaluation of a new operation technique. Fert. Steril. 25, 319.

Phadke, G. M. \& Phadke, A. G. (1967) Experiences in the reanastomosis of the vas deferens. F. Urol. 97, 888.

Scrmid, S. S. (1968) Vasectomy: indications, technic and reversibility. Fert. Steril. 19, 192. 